\title{
Ship-Ship Interactions in Calm Water and Waves. Part 1: Analysis of the Experimental Data
}

\author{
S. Maysam Mousaviraad, S. Hamid Sadat-Hosseini, Frederick Stern ${ }^{*}$ \\ IIHR-Hydroscience \& Engineering, The University of Iowa, Iowa City, IA 52242-1585, USA \\ * Corresponding author. Tel.: +1 319335 5215; fax: +1 319335 5238; E-mail: frederick- \\ stern@uiowa.edu
}

\begin{abstract}
Part 1 of this two-part paper presents detailed analysis of the previously conducted ship-ship experiments for Bob Hope and Bobo free to heave and pitch in deep calm water and waves (Van’t Veer \& Van Engelenburg, 2006). Interactions are quantified, recommendations for future experiments are provided, and the results are used as basis for selection of simulation conditions in Part 2. Calm water interactions include induced side forces and rolling and yawing moments on both ships. Effects of changing the configuration, decreasing the spacing, and increasing the speed are to intensify or diminish these induced effects, depending on the variable and the test conditions. In waves, the important effects include increased interactions in resonance region, sheltering of one ship by the other in oblique waves, and elevated amplitudes of forces and moments at high frequencies where the motion amplitudes are nearly zero. Effects of configuration, speed, and heading are studied both on trends with frequency and averaged over all frequencies,
\end{abstract}

(C) 2015. This manuscript version is made available under the Elsevier user license http://www.elsevier.com/open-access/userlicense/1.0/ 
showing different effects depending on the test conditions. Part 2 provides validation studies for selected conditions, as well as further investigation of the physics through comparison with single-ship simulations and analysis of the global and local flow variables.

Keywords: Ship-Ship Interaction; Multi-Body; Experimental Study 


\section{NOMENCLATURE}

\begin{tabular}{|c|c|}
\hline$a$ & Wave amplitude \\
\hline B & $2^{\text {nd }}$ Lt. John P. Bobo (T-AK 3008) \\
\hline$b-m$ & bow-to-amidships configuration \\
\hline CFD & Computational Fluid Dynamics \\
\hline$D$ & Data value \\
\hline$D R$ & Dynamic range (for data values) \\
\hline$E$ & Error value \\
\hline$f_{\mathrm{e}}$ & Encounter frequency \\
\hline$f_{\mathrm{n}}$ & Natural frequency \\
\hline$F r$ & Froude number \\
\hline$F r_{c}$ & Coincidence $F r$ \\
\hline $\mathrm{H}$ & Bob Hope (TAKR 300); Wave height \\
\hline$K$ & Roll moment \\
\hline$k$ & Wave number \\
\hline$L$ & Ship length \\
\hline $\mathrm{m}-\mathrm{m}$ & amidships-to-amidships configur \\
\hline
\end{tabular}




\begin{tabular}{|c|c|}
\hline$N$ & Yaw moment \\
\hline $\mathrm{PF}$ & Potential Flow \\
\hline RAO & Response Amplitude Operator \\
\hline$S$ & Spacing between ships; Simulation value \\
\hline$t$ & Time \\
\hline$T$ & Wave period \\
\hline URANS & Unsteady Reynolds Averaged Navier Stokes \\
\hline$V$ & Ship Velocity \\
\hline$X$ & Surge force \\
\hline$Y$ & Sway force \\
\hline$z$ & Heave motion \\
\hline$\alpha$ & Wave incidence angle \\
\hline$\theta$ & Pitch motion \\
\hline$\lambda$ & Wavelength \\
\hline$\sigma$ & Calm water sinkage \\
\hline$\tau$ & Calm water trim \\
\hline
\end{tabular}




\section{Introduction}

Ship-ship interactions occur in waterways with dense shipping traffic, for moored ships affected by passing ships, between tugs and vessels, and in ship to ship operations for cargo transfer. Understanding these interactions is important to avoid collisions since due to increasing ship dimensions these effects are unavoidable in channels and harbors. Also cargo transfer in waves and other environmental conditions require reliable and accurate predictions of these effects for developing design criteria and a safe envelope of operation. Reviews of ship-ship interaction studies are included in the ITTC reports by the Maneuvering Committee (ITTC, 2011). The problem has been studied using experiments, system-based methods, potential flow solvers, and viscous CFD simulations. The global variables including forces, moments, and motions are studied. The interactions are found to be functions of ship geometries and length ratio, shallow and confined water conditions, type of maneuver (overtaking, encountering, side-by-side replenishment, etc.), spacing between the ships, ship speeds, and waves and other environmental conditions. Trapping waves in the gap between two floating structures are identified, present when the spacing is a multiple of half the wavelength of the incoming waves (Mciver \& Newman, 2003). Most of the previous work are for shallow calm water conditions, while this paper focuses on deep calm water and waves.

Previous experiments are reviewed herein, while simulation studies are addressed in Part 2. All experimental studies are carried out for captive conditions only. Overtaking and encountering experiments in shallow calm water conditions are carried out systematically by a few studies (e.g. Dand, 1981; Vantorre et al., 2002) and are used to 
develop simplified theoretical and computational methods (e.g. Fang \& Kim, 1986; Kaplan \& Sankaranarayanan, 1987) and empirical formulas (e.g. Brix, 1993; Vantorre et al., 2002; Varyani et al., 2004). The effects of passing ships on moored ships in restricted water depth are tested by Pinkster \& Ruijter (2004). Captive side-by-side experiments are carried out in shallow calm water for varying conditions including water depth, drift angle, and spacing (Lataire et al., 2009) and provided as benchmark data for the $2^{\text {nd }}$ International Conference on Ship Manoeuvring in Shallow and Confined Water, 2011, Norway. The only experimental study in waves is carried out by Van't Veer \& Van Engelenburg (2006) which is the data analyzed in the current work. The experimental matrix is extensive and includes systematic experiments for replenishment and overtaking in deep calm water and waves for Bob Hope and Bobo. The experimental report did not include thorough investigation of the data to quantify and explain the ship-ship interactions including the effects of configuration, spacing, speed, and wave heading. These analyses of the data are provided in the present Part 1 paper. The data are also previously used for evaluating a set of potential flow-based computational tools, as summarized in Part 2.

The objectives of this Part 1 paper are to perform detailed analyses of the experimental data by Van't Veer \& Van Engelenburg (2006) to quantify the ship-ship interactions, provide recommendations for future experiments, and provide a basis for selection of simulation conditions in Part 2. The post-processing procedures for analysis of the data are discussed in Section 3. 


\section{The Experimental Data}

Tests were performed for the $45^{\text {th }}$ scale models of the T-AKR 300 class (Bob Hope) and the T-AK 3008 (Bobo) with main particulars shown in Table 1. All the results in this paper are in the model-scale dimensions. The length ratio of the models is $L_{H} / L_{B}=1.536$. Both models were free to pitch and heave and constrained in all other motions. Time histories of $z, \theta, X, Y, K$, and $N$ were measured. Figure 1 shows the experimental coordinate system, m-m and b-m configurations, and definition of wave heading angles. The tests were run for three separations and four speeds. Table 2 provides a complete list of all experimental tests. Each set of regular wave tests include 6 wave frequencies/wavelengths in side-by-side configurations and 3 in overtaking, for which the wave conditions are summarized in Table 3. None of these conditions correspond to the conditions where the trapping waves system is present.

\section{Post Processing Procedures}

\subsection{Analysis of Time Histories}

For calm water results the time histories of resistance, sinkage, and trim are evaluated to ensure steady state condition is achieved, and the values are obtained by averaging over the steady portions. 
Streaming value is defined as the difference between steady calm water and $0^{\text {th }}$ harmonic amplitude in waves. Following G2010 (Stern et al., 2014), only $0^{\text {th }}$ and $1^{\text {st }}$ harmonics are considered and $2^{\text {nd }}$ and higher harmonics are not included for seakeeping in regular waves.

\subsection{Maximum Response Conditions for Analysis of RAOs}

Heave and pitch maximum response conditions are studied previously for singleship RAOs (Mousaviraad et al., 2010; Sadat-Hosseini et al., 2013) and are found to be 
related to maximum wave excitation and wave radiation forces. For heave, wave excitation force is maximum at long waves and wave radiation force is maximum near the resonance condition where encounter frequency equals the ship's heave natural frequency. For a given speed and variable wavelength, the peak of heave motion occurs in long waves and near the wavelength corresponding to the resonance condition. For variable speed and wavelength, the overall peak for heave motion occurs when the two conditions overlap, which happens for infinite $F r$ since increasing ship speed shifts the resonance condition to longer waves. For pitch, wave excitation force is maximum around $\lambda / L=1.33$ and wave radiation force is maximum near the resonance condition. For a given speed and variable wavelength, the peak of pitch motion happens at a wavelength near both $\lambda / L=1.33$ and the wavelength corresponding to the resonance condition. For variable speed and wavelength, the overall peak for pitch motion occurs at the coincidence Froude number $\left(F r_{c}\right)$ where both peaks coincide. With wave encounter frequency defined as:

$$
f_{e}=\sqrt{\frac{g}{2 \pi \lambda}}-\frac{V}{\lambda} \cos \alpha
$$

where $\alpha$ is $180^{\circ}$ for head waves, the equation for $F r_{c}$ can be obtained from Eq. (2) by replacing $f_{e}$ with pitch natural frequency $f_{n, \theta}, \lambda$ with $1.33 L$, and $V$ with $F r_{c} \sqrt{L g}$ :

$$
F r_{c}=\frac{1.33}{\cos \alpha}\left[\sqrt{\frac{3}{8 \pi}}-\sqrt{\frac{L}{g}} f_{n, \theta}\right]
$$




\section{Ship-Ship Interactions in Calm Water}

\subsection{Analysis of Ship-Ship Results}

The experimental data for motions, forces, and moments are investigated for all calm water runs. The values for $\sigma$ are always negative (sink-down) for both ships. $\tau$ is always positive (bow-down) for Hope, while for Bobo it is positive in m-m configuration at $0.37 \mathrm{~m}$ spacing at both low and high speeds, and negative (bow-up) at all other conditions. $Y$ acts to move the ships closer to each other in b-m configuration, while in $\mathrm{m}$ m configuration the ships are pushed away from each other. $K$ acts to roll the ships away from each other in m-m configuration. In b-m configuration, Hope is pulled to roll toward Bobo except at $0.37 \mathrm{~m}$ spacing and $F r_{H}=0.1$, while Bobo is pushed to roll away at the highest speed $\left(F r_{H}=0.16\right)$ and pulled to roll toward Hope at smaller speeds. With Bobo to the portside of Hope, $N$ acts to move the bow of both ships to starboard in both b-m and mm configurations, except for Hope in m-m configuration at $0.067 \mathrm{~m}$ spacing and $F r_{H}=0.05$ and Bobo in b-m configuration at $0.37 \mathrm{~m}$ spacing and $F r_{H}=0.16$. Overall, the magnitudes of $Y, K$, and $N$ which are zero in the absence of the second ship are maximum in $\mathrm{m}-\mathrm{m}$ configuration at the smaller spacing $(0.37 \mathrm{~m})$ and the higher speed $\left(F r_{H}=0.16\right)$.

\subsection{Effects of Configuration, Spacing, and Speed}

The effects of configuration, spacing, and speed on calm water results based on the experimental data are summarized in Table 4. The values for individual components are percent differences, showing signs for increase or decrease. The average values are 
obtained by averaging over the absolute values to prevent the positive and negative effects to cancel each other out.

Changing configuration from $b-m$ to $m-m, \sigma$ decreases for both ships, i.e. both ships sink further down. Changes for $\tau$ are negligible (0.0\%) for Hope at all spacing and Fr conditions, except for a bow-down effect at $0.37 \mathrm{~m}$ spacing and $F r_{H}=0.16$. Bobo is affected more than hope for trim, with bow-up effect at $0.74 \mathrm{~m}$ spacing and $F r_{H}=0.1$, and bowdown effect at $0.37 \mathrm{~m}$ spacing at both ship speeds. Resistance always increases for Hope (by $16 \%$ on average), while for Bobo resistance increases by $22 \%$ at $0.067 \mathrm{~m}$ spacing and $F r_{H}=0.05$ and slightly decreases (average 3.4\%) at other conditions. $Y$ forces are induced for both ships to move them away from each other, being on average larger for Bobo (234\%) than Hope $(174 \%) . K$ moments are induced to roll the ships away from each other, being on average almost 10 times larger for Bobo than Hope. $N$ moments are induced to move the bows of both ships toward each other, being on average almost 20 times larger for Bobo than Hope. Overall, the configuration effects are larger on Bobo than Hope. For both ships, configuration effects are larger on forces and moments than motions.

By decreasing spacing from $0.74 \mathrm{~m}$ to $0.37 \mathrm{~m}, \sigma$ increases for both ships in b-m configuration, i.e. the ships rise upwards, while in m-m configuration Hope sinks further down and Bobo moves upwards at $F r_{H}=0.1$ and sinks further down at $F r_{H}=0.16$. The effect of spacing on $\tau$ is mostly negligible for Hope with only bow-down effect in m-m configuration at $F r_{H}=0.16$, while Bobo is affected more significantly with bow-down effects in $\mathrm{m}-\mathrm{m}$ and bow-up in b-m configuration. $X$ decreases for Hope by $1.4 \%$ on average, and increases for Bobo by $4.7 \%$. $Y$ forces are induced to push the ships away from 
each other in m-m configuration, while in b-m configuration the ships are pulled toward each other. The induced $Y$ forces are on average larger in m-m than b-m configuration. $K$ moments are induced to roll the ships away from each other, except for Hope in b-m configuration at $F r_{H}=0.16$ and Bobo in b-m configuration at $F r_{H}=0.1$. The induced $K$ moments are on average almost 6.5 times larger for Bobo than Hope. $N$ moments are induced for Hope to move its bow toward Bobo at $F r_{H}=0.1$ and away from Bobo at $F r_{H}=0.16$, while for Bobo the induced moments act to move its bow toward Hope in m-m configuration and away from Hope in b-m configuration. The induced $N$ moments are on average almost 3 times larger for Bobo than Hope. Overall, the spacing effects are larger on Bobo than Hope. For both ships, spacing effects are larger on forces and moments than motions.

Increasing the speed from $F r_{H}=0.1$ to $F r_{H}=0.16, \sigma$ decreases, i.e. both ships sink further down. $\tau$ increases, i.e. both ships move bow-down. $X$ increases for both ships, on average $138 \%$ for Hope and $178 \%$ for Bobo. $Y$ forces are induced to push the ships away from each other in m-m and pull the ships toward each other in b-m configuration. For Hope, $K$ moment is induced to roll it away from Bobo in $\mathrm{m}-\mathrm{m}$ and roll it toward Bobo in b$\mathrm{m}$ configuration. For Bobo, $K$ moment is always induced to roll it away from Hope. $N$ moment is induced for Hope to move its bow away from Bobo, while for Bobo $N$ moment is induced to move its bow toward Hope except in b-m configuration at $0.37 \mathrm{~m}$ spacing. Overall, the speed effects are larger on Bobo than Hope. For both ships, spacing effects are larger on forces and moments than motions. 
In summary, the effects of configuration, spacing and speed are more significant on forces and moments, than motions. The largest effects are for configuration, followed by speed. Configuration effects are most significant at the larger spacing and higher speed ( $0.74 \mathrm{~m}$ spacing and $F r_{H}=0.16$ ), followed by $0.37 \mathrm{~m}$ spacing and $F r_{H}=0.1$, and then $0.37 \mathrm{~m}$ spacing and $F r_{H}=0.16$. Spacing effects are most significant in b-m configuration at $F r_{H}=0.16$ followed by b-m configuration at $F r_{H}=0.1$. Speed effects are most significant in b-m configuration at $0.37 \mathrm{~m}$ spacing followed by $\mathrm{m}-\mathrm{m}$ configuration at $0.37 \mathrm{~m}$ spacing.

\section{Ship-Ship Interactions in Regular Waves}

\subsection{Streaming Values}

Streaming values based on the experimental data in $180^{\circ}$ and $120^{\circ}$ heading waves are summarized in Table 5. For Hope, $X$ streaming values are larger in $120^{\circ}$ heading where Hope is placed on the weather side. For Bobo, $X$ streaming values are comparable in different conditions. While in calm water $Y$ forces act to push the ships away from each other in m-m configuration, in waves the $0^{\text {th }}$ amplitudes of $Y$ act to move Hope toward Bobo and Bobo away from Hope. $Y$ streaming values in $\mathrm{m}$-m configuration are larger for Hope, especially in $120^{\circ}$ where Hope is on the weather side. $Y$ streaming values in $\mathrm{m}-\mathrm{m}$ configuration are larger in $120^{\circ}$ compared to $180^{\circ}$ for both ships. In b-m configuration, calm water $Y$ forces act to attract the ships toward each other. The $0^{\text {th }}$ amplitudes of $Y$ act in the same direction in $180^{\circ}$ waves, while in $120^{\circ}$ they act to push both ships away from each other. $Y$ streaming values in b-m configuration are larger for Bobo than Hope. In calm 
water, $K$ moments act to roll the ships away from each other in $\mathrm{m}$-m configuration, as discussed before. In waves, the $0^{\text {th }}$ amplitudes of $K$ act in the same direction in $180^{\circ}$ waves, while in $120^{\circ}$ the direction changes for Hope at $0.74 \mathrm{~m}$ spacing and for both ships at 0.37 m spacing. In b-m configuration, calm water $K$ moments act to roll Hope toward Bobo while Bobo is pushed to roll away. The $0^{\text {th }}$ amplitudes of $K$ act in opposite directions for both ships. $K$ streaming values are comparable for Hope and Bobo in $180^{\circ}$ waves, while in $120^{\circ}$ the values are larger for Bobo in $\mathrm{m}-\mathrm{m}$ and for Hope in $\mathrm{b}-\mathrm{m}$ configuration. For both ships, $K$ streaming values are much larger in $120^{\circ}$ heading compared to $180^{\circ}$. In calm water, $N$ moments act to move the bow of both ships to starboard in m-m configuration. In waves, the $0^{\text {th }}$ amplitudes of $N$ act in the same direction in $180^{\circ}$, while in $120^{\circ}$ the direction changes for Bobo. In b-m configuration, calm water $N$ moments act to move the bow of Hope to starboard and the bow of Bobo to portside. The $0^{\text {th }}$ amplitudes of $N$ act in opposite direction for Hope, moving the bow of both ships to portside. $N$ streaming values are larger in $180^{\circ}$ for Hope and in $120^{\circ}$ for Bobo. For Hope, $N$ streaming values are comparable in $180^{\circ}$ and $120^{\circ}$ waves, while for Bobo the values are significantly larger in $120^{\circ}$. Calm water sinkage and $0^{\text {th }}$ amplitudes of $z$ in waves are always negative, i.e. the ships sink downwards. Compared to calm water sinkage, the $0^{\text {th }}$ amplitudes of $z$ in waves are smaller in $180^{\circ}$, i.e. ships sink further down. In $120^{\circ}$ waves, ships sink further down in b-m configuration and move upwards in m-m configuration. For Hope, calm water trim is always bow-down. The $0^{\text {th }}$ amplitudes of $\theta$ are further bow-down in waves, except in m-m configuration at $0.37 \mathrm{~m}$ spacing in $120^{\circ}$ heading where it remains positive (bow-down) but moves slightly bow-up compared to calm water. For Bobo, calm water trim is bow-up 
(negative) in $\mathrm{m}-\mathrm{m}$ configuration at $0.74 \mathrm{~m}$ spacing. In waves, it moves slightly bow-down in $180^{\circ}$ heading, while in $120^{\circ}$ it moves all the way bow-down so that the $0^{\text {th }}$ amplitudes become positive. In m-m configuration at $0.37 \mathrm{~m}$ spacing Bobo trims bow-down in calm water. In waves, it moves further bow-down in $180^{\circ}$ heading, while in $120^{\circ}$ it moves slightly bow-up. In b-m configuration at $0.37 \mathrm{~m}$ spacing Bobo trims bow-up in calm water and moves slightly bow-down in $120^{\circ}$ waves.

Overall, the streaming values are larger in b-m configuration compared to $m-m$ configuration, and at $0.74 \mathrm{~m}$ spacing compared to $0.37 \mathrm{~m}$ spacing. Also the streaming values increase in $120^{\circ}$ heading compared to $180^{\circ}$ for forces and moments of both ships, while for motions the streaming values increase for Hope since on the weather side and decrease for Bobo since sheltered by Hope. For both ships, streaming values are larger for forces and moments than motions. The overall average values are larger for Bobo (123\%) than Hope (65\%).

\subsection{Natural Frequencies}

A two-degrees-of-freedom CFD ship-ship computation at zero speed with initial heave and pitch disturbances is carried out to determine the natural frequencies since these were not reported in the experimental study. The results are presented herein instead of in the Part 2 paper, so that the resonance frequencies, $F r_{c}$ values, and maximum response conditions could be used when discussing the seakeeping experimental results. Table 6 shows the natural frequencies as well as $F r_{c}$ values based on Eq. (3) for $180^{\circ}, 120^{\circ}$, and 
$135^{\circ}$ headings compared to $F r$ values. Natural frequencies are similar for heave and pitch, being about $0.9 \mathrm{~Hz}$ for Hope and $1.0 \mathrm{~Hz}$ for Bobo. The natural frequencies for both ships fall into the current range of encounter frequencies for all heading conditions. However, $\mathrm{Fr}$ values for all the experiments are smaller and far from $F r_{c}$ values.

\section{$5.3 \quad 0^{\text {th }}$ and $1^{\text {st }}$ Harmonic Amplitudes}

Harmonic amplitudes of motions, forces, and moments are studied for side-by-side regular wave experiments at the highest speed, $F r_{H}=0.16$, for which the interaction effects are most significant. The effects are evaluated both for trends in $1^{\text {st }}$ harmonic amplitudes versus frequency (Figures 2 to 5), and for total effects on $0^{\text {th }}$ and $1^{\text {st }}$ amplitudes averaged over all frequencies (Table 7). Note that Figures 2 through 5 include only six wave frequencies and do not provide high-resolution RAOs. The connecting lines between the data points are only intended to help with visual comparison of the data sets. Also note that since the effects are to increase responses at some frequencies and decrease at others, only absolute effects on the averaged values are reported in Table 7 to provide an evaluation of the magnitudes of the effects rather than their directions.

\subsubsection{Effects of Configuration}

Figure 2 shows the effects of configuration (m-m vs. b-m) in $120^{\circ}$ heading, for which Bobo is sheltered by Hope, especially in m-m configuration. Heave RAO for Hope 
peaks in b-m configuration, while in m-m configuration it keeps decreasing with frequency. For Bobo the effects of sheltering are prominent since heave RAO is always smaller in $\mathrm{m}$-m configuration especially in the resonance region where the difference is significant. For pitch RAOs no peak is observed in the resonance region for either of the ships and RAOs are almost always the same in both configurations. $X$ amplitudes are smaller in m-m configuration for both ships. The differences are not significant at low frequencies and in the resonance region, while at high frequencies the amplitudes increase significantly in b-m configuration. $Y$ amplitudes reduce significantly in $\mathrm{m}$-m configuration in the resonance region for both ships due to sheltering. At high frequencies, $Y$ amplitudes are elevated in $\mathrm{m}$-m configuration for both ships. $K$ amplitudes are smaller in $\mathrm{m}-\mathrm{m}$ configuration in the resonance region, and at high frequencies increase for Hope in m-m configuration. For Bobo, $K$ amplitudes increase significantly in $\mathrm{m}$-m configuration at about 0.9 and $1.4 \mathrm{~Hz}$ and in b-m configuration at about $1.2 \mathrm{~Hz} . N$ amplitudes for Hope are larger in $\mathrm{m}-\mathrm{m}$ configuration, while for Bobo $N$ amplitudes are reduced in $\mathrm{m}-\mathrm{m}$ configuration due to sheltering.

Averaged over all frequencies (Table 7), the effects of configuration are more significant on $1^{\text {st }}$ than $0^{\text {th }}$ amplitudes of $X$ and $z$ for both ships, while for other variables the effects are more significant on $0^{\text {th }}$ amplitudes. For Hope, $Y$ is affected the most (226\%) and $X$ the least (15\%). For Bobo, the most significant effect is on $N(742 \%)$ and the least on $X$ (17\%). For both ships forces and moments are affected more significantly than motions. The overall average effects are larger for Bobo (161\%) than Hope (64\%). 


\subsubsection{Effects of Spacing}

Effects of spacing are studied in m-m configuration in both $180^{\circ}$ and $120^{\circ}$ headings, as shown in Figures 3 and 4, respectively.

In $180^{\circ}$ heading, there is no sheltering and effects of spacing are mainly due to wave interactions. Decreasing spacing increases the peaks in heave RAOs of both ships, while pitch RAOs are not affected. The peak in $X$ amplitude decreases for Hope while for Bobo it is not affected by spacing. $Y$ amplitudes increase for both ships in the resonance region, with Bobo being affected more significantly. $K$ amplitudes increase for both ships in the resonance region, more significantly for Hope. $N$ amplitudes also increase in the resonance region for both ships.

In $120^{\circ}$ heading, sheltering is dominant and effects of spacing are reduced compared to $180^{\circ}$. By decreasing spacing, heave and pitch RAOs are only slightly affected. $X$ amplitudes generally decrease for both ships, especially for Bobo in the resonance region due to sheltering. $Y, K$, and $N$ amplitudes decrease significantly for both ships in the resonance region, while at higher frequencies the elevated $Y$ amplitudes are enhanced at the smaller spacing. 


\subsubsection{Effects of Heading}

Figure 5 shows the $1^{\text {st }}$ harmonic amplitudes of motions, forces, and moments for all regular wave experiments in m-m configuration at $0.37 \mathrm{~m}$ spacing and $F r_{H}=0.16$. The $\mathrm{m}-\mathrm{m}$ configuration is chosen for which sheltering effects are more significant. Spacing of 0.37 $m$ is chosen for which an examination of the data showed more significant effects. At 0.74 m spacing, same trends are observed (not shown) but with smaller magnitudes.

For heave, both Hope and Bobo peak at the resonant frequency in $180^{\circ}$. In $150^{\circ}$, heave RAO peaks for Hope, while no peak is observed for Bobo due to sheltering. In $120^{\circ}$, heave RAOs for both ships decrease with frequency with no peak. The effects of sheltering are evident since in $180^{\circ}$ heave RAO is larger for Bobo than Hope, while in oblique waves 
$\left(150^{\circ}\right.$ and $\left.120^{\circ}\right)$ heave RAOs are much smaller for Bobo compared to Hope. At low frequencies (long waves), heave RAOs are largest in $120^{\circ}$ and smallest in $180^{\circ}$ for both ships, while in the resonance region heave RAOs are largest in $180^{\circ}$ and smallest in $120^{\circ}$ waves. Heave motions are near zero at frequencies higher than $1.3 \mathrm{~Hz}$.

For pitch RAOs, different behaviors are observed for Hope and Bobo. For Hope, pitch RAOs do not peak in $180^{\circ}$ and $150^{\circ}$ headings, while in $120^{\circ}$ they increase and peak in the resonance region. For Bobo, pitch RAOs always peak in the resonance region, and are largest in $180^{\circ}$ and smallest in $120^{\circ}$ heading perhaps due to sheltering. Pitch RAOs are almost always larger for Bobo than Hope. Similar to heave, pitch motions are also almost zero at frequencies higher than $1.3 \mathrm{~Hz}$.

$X$ amplitudes of both ships peak in the resonance region. For Hope, the resonance effects are largest in $120^{\circ}$ and smallest in $180^{\circ}$, while for Bobo they are largest in $180^{\circ}$ and reduces in oblique waves $\left(150^{\circ}\right.$ and $\left.120^{\circ}\right)$ due to sheltering. A second peak is observed at about $1.4 \mathrm{~Hz}$ in $150^{\circ}$ for Hope and in $180^{\circ}$ for Bobo. For both ships, $X$ amplitudes at low frequencies are largest in $150^{\circ}$ and smallest in $120^{\circ}$, while at high frequencies $X$ amplitudes are largest in $180^{\circ}$ and smallest in $120^{\circ}$. Unlike motions, $X$ amplitudes do not approach zero at high frequencies (short waves).

$Y$ amplitudes peak in the resonance region in $180^{\circ}$ and $150^{\circ}$ for both ships, while in $120^{\circ}$ no peak is observed for either of the ships. For both ships, $Y$ amplitudes in the resonance region are largest in $180^{\circ}$ followed by $150^{\circ}$. A second peak is observed for both ships at around 1.4 Hz. $Y$ amplitudes are larger for Hope, which is on the weather side, at 
almost all frequencies. At small frequencies $Y$ amplitudes are largest in $120^{\circ}$ and smallest in $180^{\circ}$ for both ships.

$K$ amplitudes show different behaviors for Hope and Bobo. For Hope, $K$ amplitudes are reduced and reach minimum in the resonance region, being most noticeable in $180^{\circ}$ and least in $150^{\circ}$. For Bobo, $K$ amplitudes peak in the resonance region being largest in $120^{\circ}$ and smallest in $180^{\circ}$. A second peak is observed for $K$ amplitudes of both ships, at a frequency of about $1.4 \mathrm{~Hz}$ for Hope, and at the two highest frequencies for Bobo. The second peak is more prominent for Hope than Bobo, and in $120^{\circ}$ heading for both ships. $K$ amplitudes are almost always larger for Hope than Bobo, except in the resonance region and at the highest frequency to where the second peak effects extend for Bobo.

$N$ amplitudes show different trends in different heading angles. In $180^{\circ}, N$ amplitudes are minimum at the resonant frequency and peak at about $1.2 \mathrm{~Hz}$ for both ships. In $150^{\circ}, N$ amplitudes are minimum at the resonant frequency and then keeps increasing for the next two frequencies for Hope, while for Bobo the curve is almost flat with a slight peak at $1.2 \mathrm{~Hz}$. In $120^{\circ}, N$ amplitudes behave differently from the other two headings: they peak in the resonance region and reach values higher than other wave headings. For Hope the peak is at about $1 \mathrm{~Hz}$ while for Bobo it occurs at about $1.2 \mathrm{~Hz} . N$ amplitudes are almost always larger for Hope than Bobo, which is sheltered by Hope. At low frequencies (long waves), $N$ amplitudes are largest in $120^{\circ}$ and smallest in $180^{\circ}$ for Hope, and the other way around for Bobo. At high frequencies, $N$ amplitudes are largest in $150^{\circ}$ and smallest in $180^{\circ}$ 


\section{Conclusions and Future Work}

In Part 1 of this two-part paper, detailed analyses are carried out on the ship-ship experimental data by Van’t Veer \& Van Engelenburg (2006) on Bob Hope and Bobo free to heave and pitch in deep calm water and waves. The interactions are quantified, the effects of configuration, spacing, speed, and wave heading are studied, recommendations are provided for future experimental studies, and the results are used as basis for selection of simulation conditions in Part 2.

Calm water interactions in m-m configuration include induced $Y$ force to push the ships away from each other, $K$ moment to roll the ships away from each other, and $N$ moment to move the bow of Bobo toward Hope and the bow of Hope away from Bobo. The effects of changing configuration from $b-m$ to $m-m$, decreasing the spacing between 
the ships, and increasing the speed are generally to intensify the magnitudes of the induced forces and moments, although in some cases the directions are changed. Overall, the effects are more significant on Bobo than Hope, and are larger for forces and moments than motions.

In waves, the streaming values as well as $0^{\text {th }}$ and $1^{\text {st }}$ harmonic amplitudes are studied. The streaming values are larger in b-m configuration compared to m-m configuration, and at $0.74 \mathrm{~m}$ spacing compared to $0.37 \mathrm{~m}$ spacing. Also the streaming values increase in $120^{\circ}$ heading compared to $180^{\circ}$ for forces and moments of both ships, while for motions the streaming values increase for Hope, which is on the weather side, and decrease for Bobo, which is sheltered by Hope.

Natural frequencies for heave and pitch motions are calculated by performing zerospeed ship-ship CFD computations with initial heave and pitch disturbances. The natural frequencies for both ships fall into the current range of encounter frequencies, while the current $F r$ values are smaller and far from the $F r_{c}$ values.

For $1^{\text {st }}$ harmonic amplitudes versus frequency, the most important physics include increased interactions in resonance region, sheltering of Bobo by Hope in oblique waves, and second peaks occurring at high frequencies for $X, Y, K$, and $N$. These second peaks are perhaps due to the diffracted transverse wave system in the gap between the ships, similar to but not necessarily the same as the trapping waves explained by Mciver \& Newman (2003), since at these high frequencies the motions are nearly zero and the effects are not related to increased ship motions. Note that trapping waves will occur for smaller 
wavelengths (higher frequencies) than the current frequency range, at which the amplitudes are expected to increase even further.

Effects of configuration, spacing, and wave heading are studied both for $1^{\text {st }}$ harmonic amplitudes versus frequency and for total effects on $0^{\text {th }}$ and $1^{\text {st }}$ harmonics averaged over all wave frequencies. In head waves, decreasing the spacing intensifies the interaction effects in the resonance region. In oblique waves, changing the configuration and heading intensifies sheltering effects, i.e. the amplitudes reduce significantly for the sheltered ship, the resonance interactions diminish, and the elevated amplitudes at high frequencies amplify. Averaged over all frequencies, the effects of configuration in $120^{\circ}$ heading are more significant on Bobo than Hope, while the effects of spacing in $120^{\circ}$ heading and the effects of heading at both spacing conditions are more significant on Hope than Bobo. These are expected and are due to sheltering of Bobo by Hope in m-m configuration in $120^{\circ}$ waves. In head waves, however, the effects are comparable for the two ships. Overall, heading effects are most significant, followed by configuration, while the effects of spacing are relatively smaller.

Part 2 provides validation studies for selected conditions, as well as further investigation of the physics through comparison with single-ship simulations and analysis of the global and local flow variables.

Future experimental studies will need to include experimental uncertainty analysis to be used for CFD verification and validation (V\&V) studies. Also the experiments need to include the conditions corresponding to trapping waves and coincidence Froude 
numbers. Captive experiments will need to extend for ship-ship interactions in shallow and confined water and for different geometries with different length ratios. Next step will need to extend to free-running experiments with propulsors and controllers for resistance and propulsion, seakeeping, course keeping, and maneuvering in calm water and regular and irregular seas in deep and shallow conditions.

\section{Acknowledgments}

This work was sponsored by the Office of Naval Research under Grant N00014-011-0073, administered by Dr. Thomas Fu.

\section{References}

Brix, J., 1993. Manoeuvring Technical Manual. Seehafen Verlag, Hamburg, Germany. ISBN: 3-87743-902-0.

Dand, I.W., 1981. Some Measurements in Interaction Between Ship Models Passing On Parallel Courses. National Maritime Institute Report 108.

Fang, M.C., Kim, C.H., 1986. Hydrodynamically Coupled Motions of Two Ships Advancing in Oblique Waves. Journal of Ship Research 30 (3), 159-171. 
ITTC, 2011. The Manoeuvring Committee Final Report and Recommendations to the $26^{\text {th }}$ ITTC. In: Proceedings of the $26^{\text {th }}$ International Towing Tank Conference, Rio de Janeiro, Brazil.

Kaplan, P., Sankaranarayanan, K., 1987. Hydrodynamic Interaction Of Ships In Shallow Channels, Including Effects Of Asymmetry. In: International Conference on Ship Manoeuvrability, London, United Kingdom.

Lataire, E., Vantorre, M., Delefortrie, G., 2009. Captive Model Testing for Ship-to-ship Operations. In: International Conference on Marine Simulation and Ship Maneuverability 2006 (MARSIM'06), Panama City, Panama.

Mciver, P., Newman, J.N., 2003. Trapping Structures In The Three-Dimensional WaterWave Problem. Journal of Fluid Mechanics 484, 283-301.

Mousaviraad, S.M., Carrica, P.M., Stern, F., 2010. Development and validation of harmonic wave group single-run procedure for RAO with comparison to regular wave and transient wave group procedures using URANS. Ocean Engineering 37 (8-9), 653-666.

Pinkster, J.A., Ruijter, M.N., 2004. The influence of passing ships on ships moored in restricted waters. In: Proceedings of the Offshore Technology Conference (OTC 04), Huston, Texas, USA.

Sadat-Hosseini, H., Wu, P.C., Carrica, P.M., Kim, H., Toda, Y., Stern, F., 2013. CFD Verification and Validation of Added Resistance and Motions of KVLCC2 with 
Fixed and Free Surge in Short and Long Head Waves. Ocean Engineering 59, 240273.

Silver, A.L., Hughes, M.J., Conard, R.E., Lee, S.S., Klamo, J.T., Park, J.T., 2008. Evaluation of Multi-Vessel Ship Motion Prediction Codes. Naval Surface Warfare Center Carderock Division, Report NSWCCD-50-TR-2008/070.

Stern, F., Sadat-Hosseini, S.H., Mousaviraad, S.M., Bhushan, S., 2014. Chapter 4Evaluation of Seakeeping Predictions. In: Numerical Ship Hydrodynamics- An assessment of the Gothenburg 2010 Workshop, by Larsson, Lars; Stern, Frederick; Visonneau, Michel (Eds.), pp. 141-202, Springer.

Van’t Veer, A.P., Van Engelenburg R., 2006. Multivessel Tests TAKR 300 (Bob Hope) \& T-AK 3008 (2 ${ }^{\text {nd }}$ Lt. John P. Bobo). Computer Sciences Corporation/Advanced Marine Center, Report No. 19037-3-SMB.

Vantorre, M., Verzhbitskaya, E., Laforce, E., 2002. Model Test Based Formulations of Ship-Ship Interaction Forces. Ship Technology Research 49, 124-141.

Varyani, K. S., Thavalingam, A., Krishnankutty P., 2004. New generic mathematical model to predict hydrodynamic interaction effects for overtaking maneuvers in simulators. Journal of Marine Science and Technology 9 (1), 24-31. 
Table 1: Main particulars of Hope and Bobo

\begin{tabular}{|c|c|c|c|c|}
\hline \multirow{2}{*}{} & \multicolumn{2}{|c|}{ Full Scale } & \multicolumn{2}{c|}{ Model Scale } \\
\cline { 2 - 5 } & $\mathrm{H}$ & $\mathrm{B}$ & $\mathrm{H}$ & $\mathrm{B}$ \\
\hline$L_{\mathrm{WL}}(\mathrm{m})$ & 279.16 & 181.689 & 6.20 & 4.04 \\
\hline$B(\mathrm{~m})$ & 32.258 & 32.156 & 0.72 & 0.71 \\
\hline$T_{\mathrm{F}}(\mathrm{m})$ & 7.83 & 5.19 & 0.17 & 0.12 \\
\hline$T_{\mathrm{A}}(\mathrm{m})$ & 9.76 & 8.18 & 0.22 & 0.18 \\
\hline$\Delta($ tons $)$ & 50396.7 & 30784.9 & 0.55 & 0.34 \\
\hline$C_{\mathrm{B}}$ & 0.643 & 0.746 & 0.643 & 0.746 \\
\hline
\end{tabular}

Table 2: List of all experimental tests. Experiments in waves are carried out for 6 wave frequencies in sideby-side and 3 wave frequencies in overtaking conditions as per next Table.

\begin{tabular}{|c|c|c|c|c|c|c|}
\hline \multirow{2}{*}{ Configuration } & \multirow{2}{*}{$\begin{array}{l}\text { Spacing } \\
(\mathrm{m})\end{array}$} & \multicolumn{3}{|c|}{ Speed } & \multirow{2}{*}{ Heading (deg) } & \multirow{2}{*}{$\begin{array}{l}\text { No. of } \\
\text { Runs }\end{array}$} \\
\hline & & $(\mathrm{m} / \mathrm{s})$ & $F r_{H}$ & $F r_{B}$ & & \\
\hline m-m;b-m & 0.067 & 0.38 & 0.05 & 0.06 & Calm Water & 2 \\
\hline m-m;b-m & $0.37 ; 0.74$ & $0.77 ; 1.23$ & $0.1 ; 0.16$ & $0.12 ; 0.19$ & Calm Water & 8 \\
\hline Overtaking & 0.37 & Hope:0.77; Bobo:1.23 & 0.1 & 0.19 & Calm Water & 1 \\
\hline Overtaking & 0.37 & Hope:1.23; Bobo:0.77 & 0.16 & 0.12 & Calm Water & 1 \\
\hline m-m;b-m & 0.067 & $0 ; 0.38$ & $0 ; 0.05$ & $0 ; 0.06$ & $0 ; 90 ; 180 ; 270$ & $16 \times 6$ \\
\hline m-m & 0.067 & $0 ; 0.38$ & $0 ; 0.05$ & $0 ; 0.06$ & $45 ; 135 ; 225 ; 315$ & $8 \times 6$ \\
\hline m-m & 0.74 & 0.77 & 0.1 & 0.12 & $120 ; 150 ; 180$ & $3 \times 6$ \\
\hline m-m; b-m & $0.37 ; 0.74$ & 1.23 & 0.16 & 0.19 & $120 ; 150 ; 180$ & $12 \times 6$ \\
\hline $\mathrm{m}-\mathrm{m}$ & 0.74 & 1.23 & 0.16 & 0.19 & $\begin{array}{c}0 ; 30 ; 60 ; 90 ; 210 ; 240 ; 270 \\
300 ; 330\end{array}$ & $9 \times 6$ \\
\hline Overtaking & $0.37 ; 0.74$ & Hope:0.77; Bobo:1.23 & 0.1 & 0.19 & $90 ; 120 ; 150 ; 180$ & $8 \times 3$ \\
\hline Overtaking & $0.37 ; 0.74$ & Hope:1.23; Bobo:0.77 & 0.16 & 0.12 & $90 ; 120 ; 150 ; 180$ & $8 \times 3$ \\
\hline
\end{tabular}

Table 3: Wave conditions for each set of seakeeping experiments: 6 wave frequencies per side-by-side and 3 per overtaking experiments.

\begin{tabular}{|c|c|c|c|c|c|c|c|}
\hline Frequency $(\mathrm{rad} / \mathrm{s})$ & $\lambda(\mathrm{m})$ & $\lambda / L_{\mathrm{H}}$ & $\lambda / L_{\mathrm{B}}$ & $a(\mathrm{~m})$ & $a k$ & $H / \lambda$ & Overtaking \\
\hline 2.68 & 8.56 & 1.38 & 2.12 & 0.0167 & 0.012 & $1 / 257$ & \\
\hline 3.35 & 5.48 & 0.88 & 1.36 & 0.0167 & 0.019 & $1 / 165$ & Yes \\
\hline 4.02 & 3.80 & 0.61 & 0.94 & 0.0167 & 0.029 & $1 / 110$ & \\
\hline 4.70 & 2.80 & 0.45 & 0.69 & 0.0167 & 0.038 & $1 / 83$ & Yes \\
\hline 5.37 & 2.14 & 0.34 & 0.53 & 0.0167 & 0.049 & $1 / 64$ & Yes \\
\hline 6.37 & 1.52 & 0.24 & 0.38 & 0.0167 & 0.069 & $1 / 45$ & \\
\hline
\end{tabular}


Table 4: Effects of configuration, spacing, and speed on calm water experimental data

\begin{tabular}{|c|c|c|c|c|c|c|c|c|c|c|c|c|c|c|c|}
\hline \multirow{2}{*}{ Effects } & \multirow{2}{*}{ Config. } & \multirow{2}{*}{$\begin{array}{c}\text { Spacing } \\
\text { (m) }\end{array}$} & \multirow{2}{*}{$\begin{array}{l}\text { Speed } \\
\left(F r_{H}\right)\end{array}$} & \multicolumn{6}{|c|}{ Hope } & \multicolumn{6}{|c|}{ Bobo } \\
\hline & & & & $\sigma$ & $\tau$ & $X$ & $Y$ & $K$ & $N$ & $\sigma$ & $\tau$ & $X$ & $Y$ & $K$ & $N$ \\
\hline \multirow{6}{*}{ Config. } & \multirow{5}{*}[(\mathrm{m}-\mathrm{m})-(\mathrm{b}-\mathrm{m})]{$/(\mathrm{b}-\mathrm{m}) \times 100$} & 0.067 & 0.047 & -100.0 & 0.0 & 60.7 & -181.4 & 191.5 & 113.1 & -66.7 & 0.0 & 22.0 & 289.9 & -226.3 & -478.6 \\
\hline & & 0.37 & 0.094 & -160.0 & 0.0 & 6.9 & -227.2 & 29.9 & 93.2 & -100.0 & 133.3 & -2.1 & 261.6 & -2722.4 & -3186.2 \\
\hline & & 0.74 & 0.094 & -10.0 & 0.0 & 4.4 & -150.4 & 395.4 & 88.9 & -75.0 & -700.0 & -8.6 & 197.2 & -1566.0 & -301.2 \\
\hline & & 0.37 & 0.16 & -100.0 & 100.0 & 3.2 & -166.8 & 307.1 & 49.7 & -66.7 & 200.0 & -0.3 & 214.2 & -253.0 & -3653.7 \\
\hline & & 0.74 & 0.16 & -18.8 & 0.0 & 4.0 & -143.2 & 287.8 & 72.5 & -32.0 & 0.0 & -2.6 & 205.1 & -7438.9 & -901.1 \\
\hline & \multicolumn{3}{|c|}{ Average of absolute values } & 77.8 & 20.0 & 15.9 & 173.8 & 242.3 & 83.5 & 68.1 & 206.7 & 7.1 & 233.6 & 2441.3 & 1704.2 \\
\hline \multirow{5}{*}{ Spacing } & $\mathrm{m}-\mathrm{m}$ & \multirow{4}{*}{ (small-large)/large $\times 100$} & 0.094 & -18.2 & 0.0 & -1.2 & -175.6 & 74.5 & 41.1 & 14.3 & 112.5 & 8.8 & 154.1 & -84.2 & -133.0 \\
\hline & b-m & & 0.094 & 50.0 & 0.0 & -3.6 & 9.3 & 496.8 & 4.4 & 25.0 & -200.0 & 1.6 & -52.9 & 3.0 & 71.6 \\
\hline & $\mathrm{m}-\mathrm{m}$ & & 0.16 & -15.8 & 100.0 & -0.8 & -103.6 & 60.1 & -92.1 & -6.1 & 200.0 & 5.5 & 97.6 & -101.0 & -95.0 \\
\hline & b-m & & 0.16 & 31.3 & 0.0 & 0.0 & 31.9 & -45.1 & -5.1 & 16.0 & 0.0 & 3.0 & -81.8 & -4193.2 & 154.9 \\
\hline & \multicolumn{3}{|c|}{ Average of absolute values } & 28.8 & 25.0 & 1.4 & 80.1 & 169.1 & 35.7 & 15.3 & 128.1 & 4.7 & 96.6 & 1095.3 & 113.6 \\
\hline \multirow{5}{*}{ Speed } & $\mathrm{m}-\mathrm{m}$ & 0.37 & \multirow{5}{*}{ (high-low)/low $\times 100$} & -69.2 & 100.0 & 135.8 & -66.7 & 189.3 & -1293.8 & -94.4 & 100.0 & 179.0 & 121.2 & -173.9 & -160.9 \\
\hline & b-m & 0.37 & & -120.0 & 0.0 & 144.3 & 217.8 & -281.5 & -89.9 & -133.3 & 33.3 & 174.0 & -213.0 & -2134.4 & 341.3 \\
\hline & $m-m$ & 0.74 & & -72.7 & 0.0 & 134.8 & -125.7 & 215.4 & -327.5 & -57.1 & 75.0 & 188.0 & 184.4 & -150.9 & -211.8 \\
\hline & b-m & 0.74 & & -60.0 & 0.0 & 135.5 & 163.2 & -396.1 & -72.7 & -108.3 & 100.0 & 170.2 & -163.2 & -148.8 & -25.0 \\
\hline & \multicolumn{2}{|c|}{ Average of absolute values } & & 80.5 & 25.0 & 137.6 & 143.3 & 270.6 & 445.9 & 98.3 & 77.1 & 177.8 & 170.5 & 652.0 & 184.7 \\
\hline
\end{tabular}

Table 5: Streaming results $\left(\left|\frac{D_{\text {waves }}-D_{\text {calm }}}{D_{\text {calm }}}\right| \times 100\right)$ at $F r_{\mathrm{H}}=0.16$

\begin{tabular}{|c|c|c|c|c|c|c|c|c|c|c|c|c|}
\hline & \multirow{2}{*}{\multicolumn{6}{|c|}{ Hope }} & \multirow{2}{*}{\multicolumn{6}{|c|}{ Bobo }} \\
\hline & & & & & & & & & & & & \\
\hline & $X$ & $Y$ & $K$ & $N$ & $z$ & $\theta$ & $X$ & $Y$ & $K$ & $N$ & $z$ & $\theta$ \\
\hline $\mathrm{m}-\mathrm{m} ; S_{0.74} ; 180$ & 3.96 & 126.51 & 52.45 & 95.35 & 6.14 & 33.33 & 7.57 & 33.85 & 59.45 & 24.10 & 36.36 & 716.67 \\
\hline $\mathrm{m}-\mathrm{m} ; S_{0.37} ; 180$ & 3.57 & 104.55 & 38.55 & 45.78 & 10.61 & 25.00 & 6.34 & 43.00 & 45.02 & 12.96 & 5.71 & 58.33 \\
\hline $\mathrm{m}-\mathrm{m} ; S_{0.74} ; 120$ & 6.77 & 370.46 & 93.79 & 144.88 & 21.05 & 16.67 & 6.30 & 115.24 & 296.55 & 265.56 & 19.70 & 191.67 \\
\hline $\mathrm{m}-\mathrm{m} ; S_{0.37} ; 120$ & 4.93 & 234.82 & 144.94 & 77.92 & 28.79 & 66.67 & 6.42 & 120.50 & 232.66 & 241.71 & 20.48 & 41.67 \\
\hline b-m; $S_{0.37} ; 120$ & 8.18 & 131.58 & 330.33 & 69.61 & 30.30 & 16.67 & 4.67 & 258.04 & 200.93 & 532.79 & 3.97 & 100.00 \\
\hline \multirow{3}{*}{ Average } & 5.48 & 193.58 & 132.01 & 86.71 & 19.38 & 31.67 & 6.26 & 114.13 & 166.92 & 215.42 & 17.24 & 221.67 \\
\hline & \multicolumn{4}{|c|}{104.45} & \multicolumn{2}{|c|}{25.52} & \multicolumn{4}{|c|}{125.68} & \multicolumn{2}{|c|}{119.46} \\
\hline & \multicolumn{6}{|c|}{64.98} & \multicolumn{6}{|c|}{122.57} \\
\hline
\end{tabular}


Table 6: Natural frequencies for heave and pitch of Hope and Bobo and $F r_{c}$ values compared to current $F r$

\begin{tabular}{|c|c|c|c|}
\hline & $\mathrm{H}$ & B \\
\hline \multicolumn{4}{|c|}{ Heave and Pitch Natural Frequency } \\
\hline \multicolumn{2}{|c|}{$f_{n, z}(\mathrm{~Hz})$} & 0.91 & 0.98 \\
\hline \multicolumn{2}{|c|}{$f_{n, \theta}(\mathrm{Hz})$} & 0.89 & 1.07 \\
\hline \multicolumn{4}{|c|}{ Coincidence Froude/Current Fr } \\
\hline \multirow{2}{*}{$180^{\circ}$} & $F r_{c}$ & 0.48 & 0.45 \\
\hline & $F r$ & 0.16 & 0.19 \\
\hline \multirow{2}{*}{$120^{\circ}$} & $\overline{F r}$ & 0.96 & 0.91 \\
\hline & $F r$ & 0.16 & 0.19 \\
\hline \multirow{2}{*}{$135^{\circ}$} & $F r_{c}$ & 0.68 & 0.64 \\
\hline & $F r$ & 0.05 & 0.06 \\
\hline
\end{tabular}

Table 7: Effects of configuration, spacing, and wave heading on regular wave experimental data

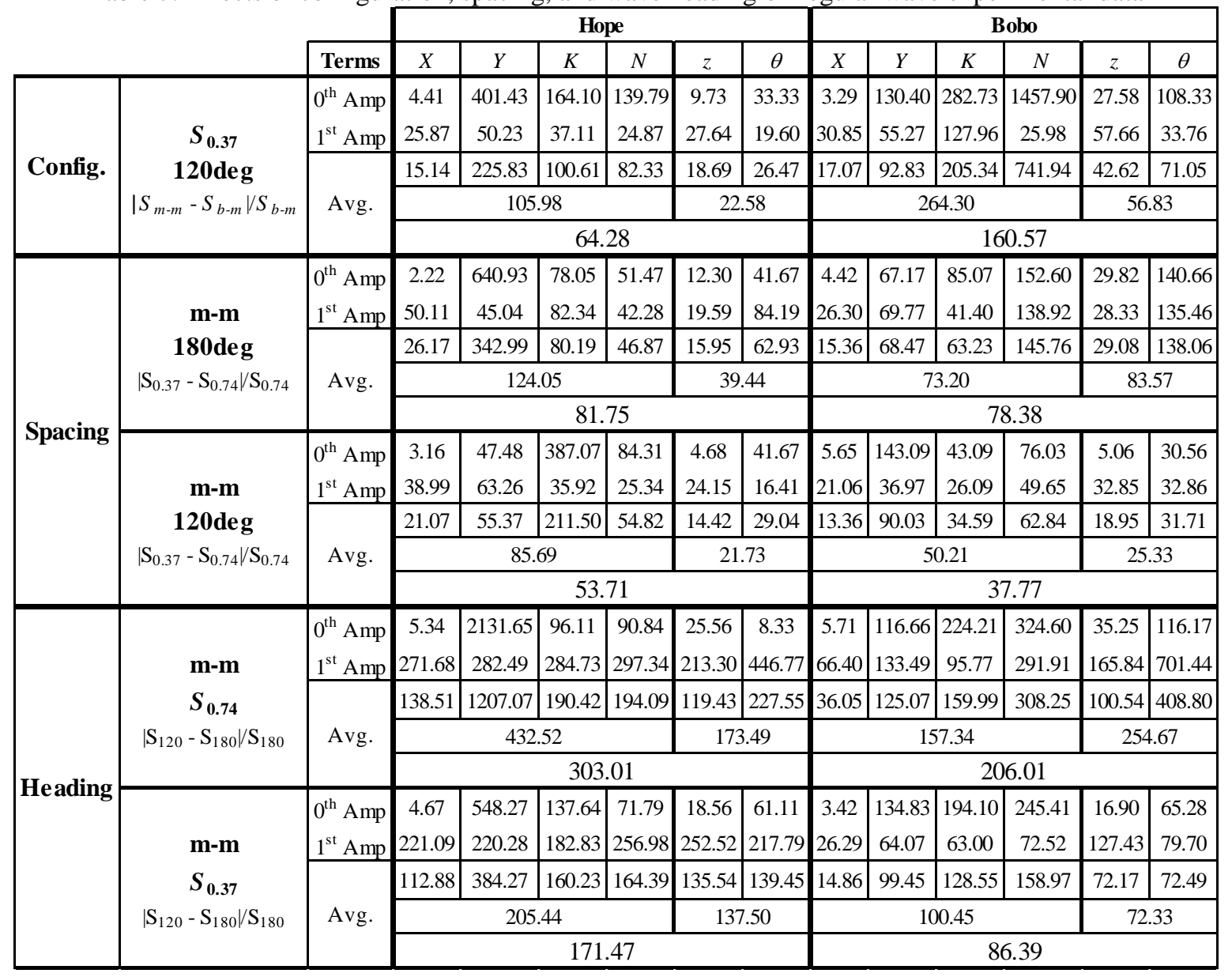




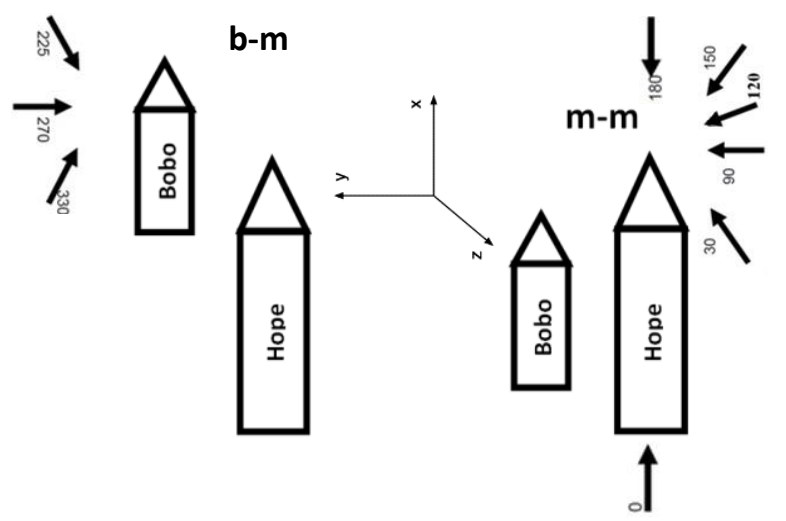

Figure 1: Definitions of m-m and b-m configurations, coordinates, and wave heading directions 
Effect of Configuration- Bobo: $120 \mathrm{deg}$

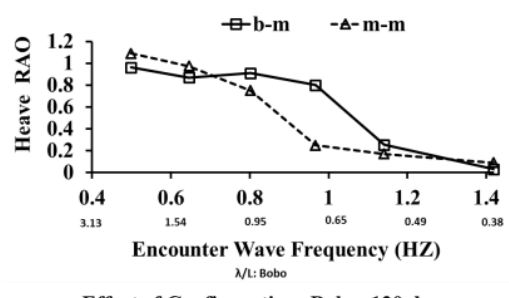

Effect of Configuration- Bobo: $120 \mathrm{deg}$

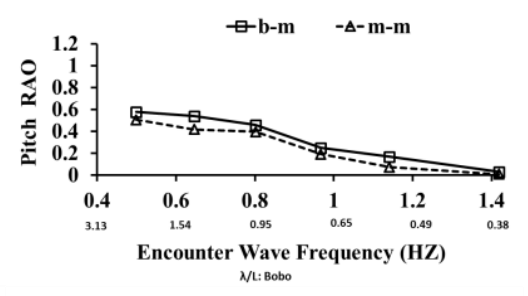

Effect of Configuration- Bobo: $120 \mathrm{deg}$

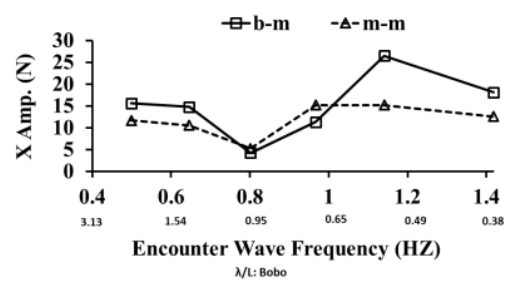

Effect of Configuration- Bobo: $120 \mathrm{deg}$

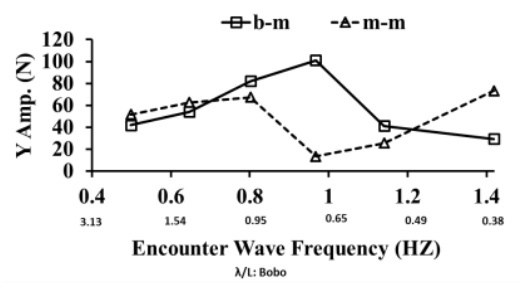

Effect of Configuration- Bobo: $120 \mathrm{deg}$

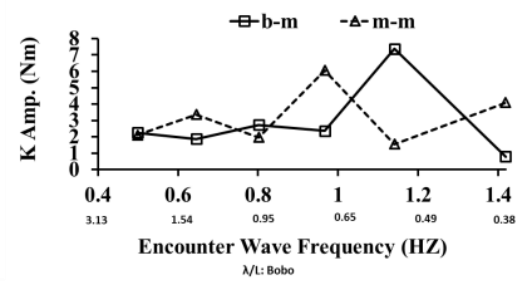

Effect of Configuration- Bobo: $120 \mathrm{deg}$
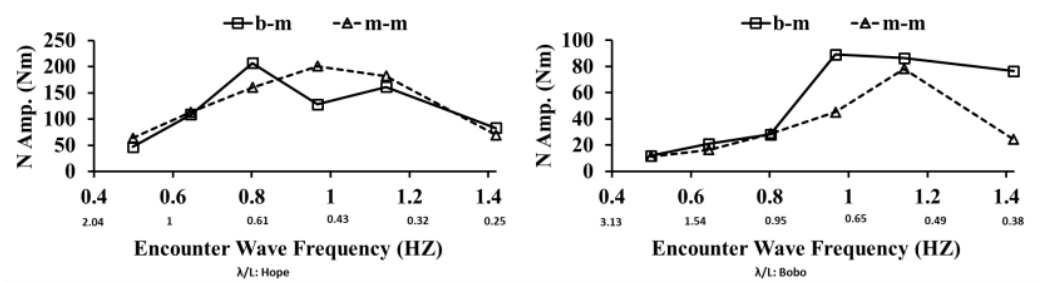

Figure 2: Effects of configuration (m-m vs. b-m) at $0.37 \mathrm{~m}$ spacing and $F r_{\mathrm{H}}=0.16$ in $120^{\circ}$ heading 


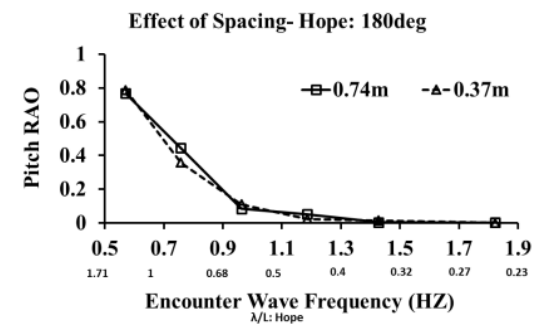

Effect of Spacing- Hope: 180deg

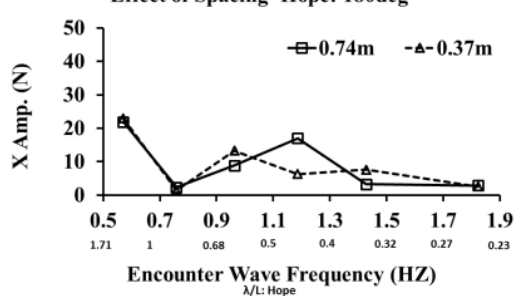

Effect of Spacing- Hope: 180deg
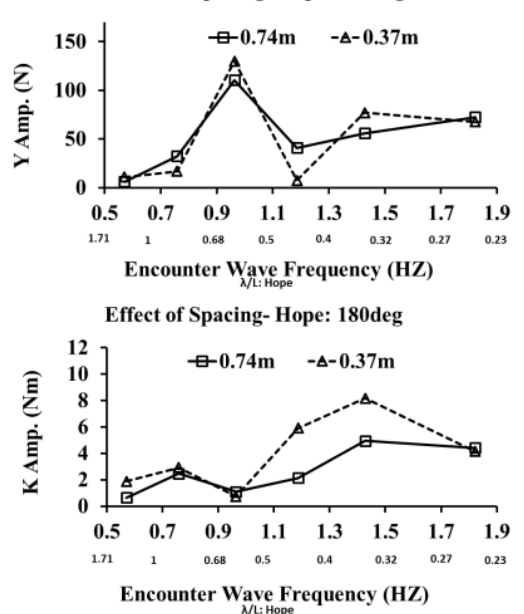

Effect of Spacing- Hope: 180deg

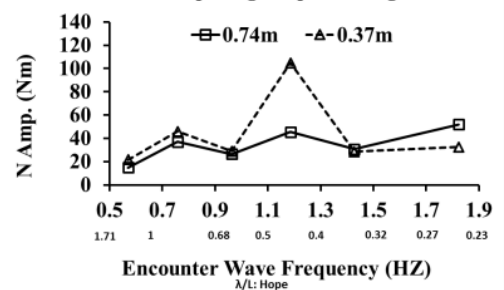

Figure 3: Effects of spacing in m-m configuration and $180^{\circ}$ heading at $F r_{\mathrm{H}}=0.16$
Effect of Spacing- Bobo: 180deg

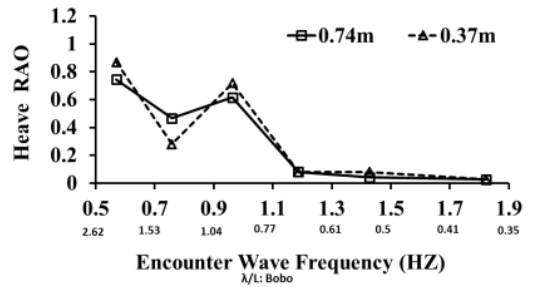

Effect of Spacing- Bobo: 180deg

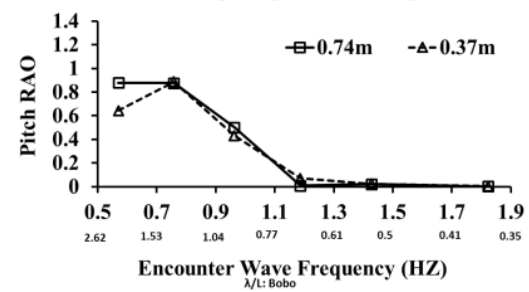

Effect of Spacing- Bobo: 180deg

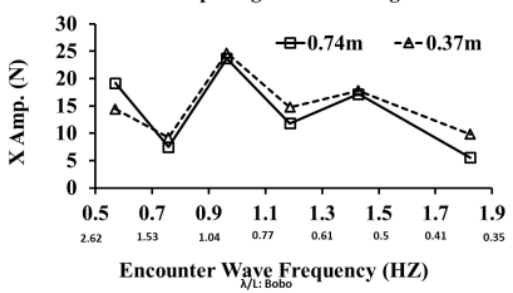

Effect of Spacing- Bobo: 180deg

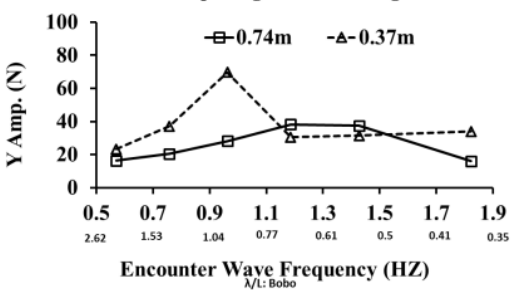

Effect of Spacing- Bobo: 180deg
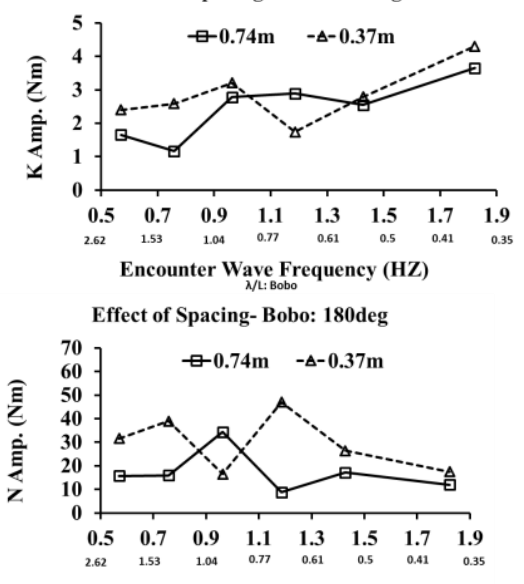

Encounter Wave Frequency (HZ) 


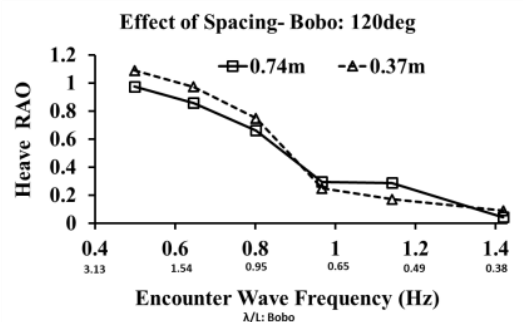

Effect of Spacing- Bobo: 120deg
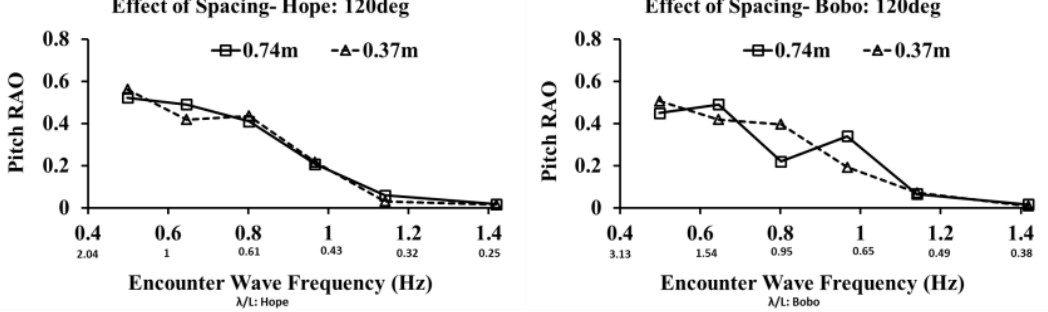

Effect of Spacing- Bobo: 120deg
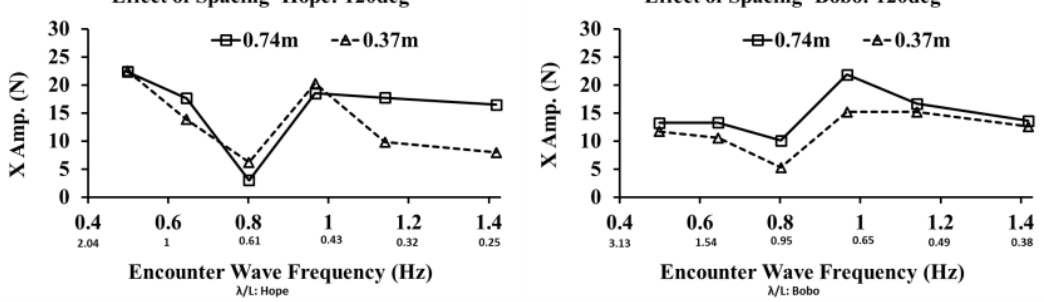

Effect of Spacing- Bobo: 120deg
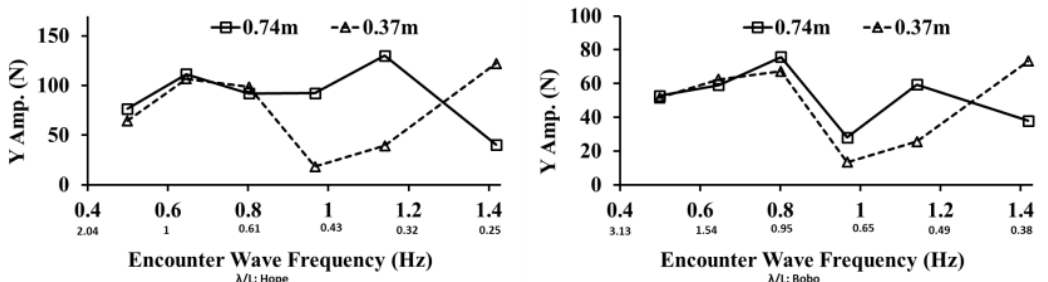

Effect of Spacing- Bobo: 120deg

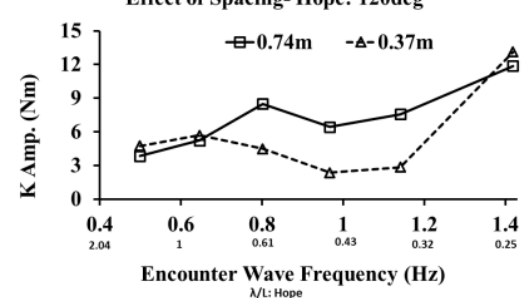

Effect of Spacing- Hope: 120deg
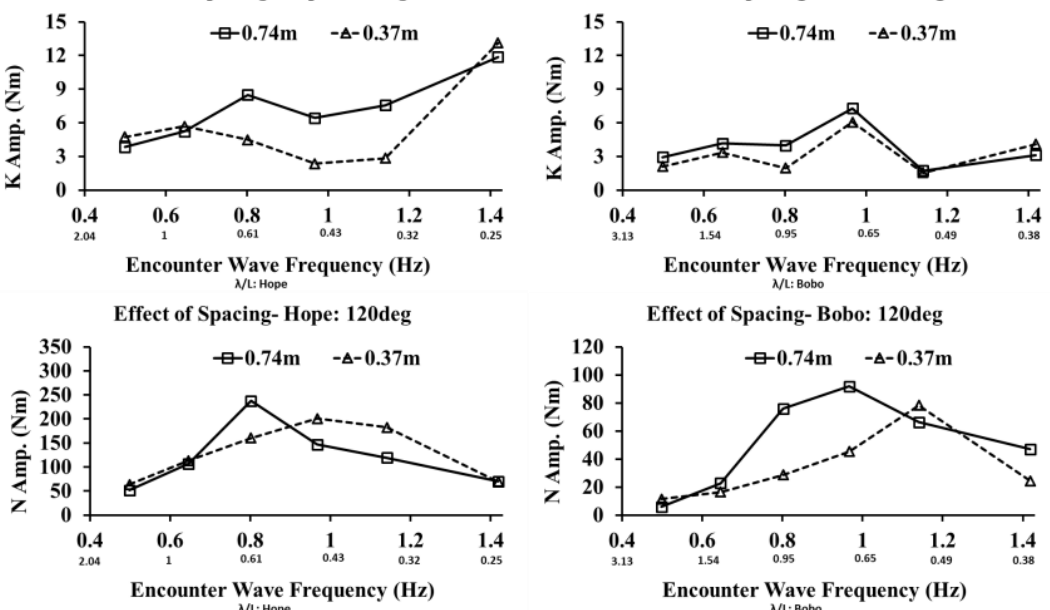

Effect of Spacing- Bobo: 120deg

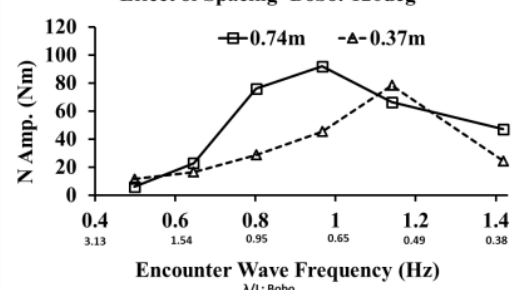

Figure 4: Effects of spacing in m-m configuration and $120^{\circ}$ heading at $F r_{\mathrm{H}}=0.16$ 
